\title{
AVALIAÇÃO TÉCNICA E ECONÔMICA DO HARVESTER EM DIFERENTES CONDIÇÕES OPERACIONAIS ${ }^{1}$
}

Everson Ramos Burla ${ }^{2}$, Haroldo Carlos Fernandes ${ }^{3}$, Carlos Cardoso Machado ${ }^{4}$, Daniel Mariano Leite ${ }^{5}$, Paula Santana Fernandes ${ }^{6}$

\begin{abstract}
RESUMO
Este estudo foi conduzido em povoamentos de eucalipto de uma empresa florestal situada no Estado de Minas Gerais, com o objetivo de avaliar técnica e economicamente a máquina colhedora de árvores Harvester em diferentes condições de declividade do terreno e produtividade florestal. A análise técnica consistiu de um estudo de tempo e movimentos com o objetivo de identificar os elementos do ciclo operacional da máquina, bem como suas variações em função da declividade do terreno e produtividade florestal. A análise econômica consistiu na determinação dos custos operacionais. A declividade do terreno foi estratificada em plana, ondulada e acidentada, e a produtividade florestal em baixa, média e alta. Foi utilizada a amostragem casual simples em nove diferentes situações relacionando a declividade e a produtividade florestal. Foi determinado o tempo gasto para a máquina processar e calculado o rendimento em todas as situações. De acordo com os resultados obtidos, concluiu-se que o rendimento diminui com o aumento da declividade e aumenta com o aumento do volume individual das árvores até um ponto máximo, a partir do qual tende a diminuir.
\end{abstract}

Palavras-chave: mecanização; colheita florestal; custo operacional

ABSTRACT

TECHNICAL AND ECONOMICAL EVALUATION OF A HARVESTER IN LOGGING UNDER DIFFERENT SLOPES AND FORESTRY YIELD

This study was done in a eucalypt plantation of the Minas Gerais state forestry company, to technically and economically evaluate a harvester machine in different terrain slopes and forestry yield. The technical analysis involved time and movements to identify the operational cycle elements and their variations due to the terrain slopes and yield. The economical analysis involved determining operational costs. The terrain slope was classified as flat, wavy and rough and the plantation was divided into low, medium and high yield plots. The simple random sampling was used in nine different situations related to slope and yield. The time spent to process each plot and its yield was determined. The data showed that harvester's yield decreases with the increasing slope, but increases with increasing individual tree volume to certain point and then tends to decrease.

Keywords: mechanization; forest harvester; operational cost

\footnotetext{
Recebido para publicação em 19/03/2010. Aprovado em 07/10/2011.

1- Parte da dissertação de mestrado do primeiro autor, DEA/UFV. Apoio financeiro do CNPq

2- Eng. Florestal, Eldorado Celulose e Papel S/A, everson.burla@eldorado.com.br

3- Eng. Agrícola, Professor Associado, DEA/UFV, Viçosa - MG, haroldo@ufv.br

4- Eng. Florestal, Professor Titular, DEF/UFV, Viçosa - MG, machado@ufv.br

5- Lic. em Ciências Agrícolas, Doutorando em Engenharia Agrícola, UFV, Viçosa - MG, daniel.mariano@ufv.br

6- Graduanda em Administração de Empresas, UFV, Viçosa - MG, paulasantanf@gmail.com
}

\section{REVENG}

412-422 p. 


\section{INTRODUÇÃO}

O setor florestal se destaca como importante e relevante para o Brasil em diversas áreas. Do ponto de vista econômico, o setor florestal brasileiro tem sido responsável, anualmente, na formação econômica do País, por aproximadamente $4 \%$ do produto interno bruto (PIB), gerando 680.000 empregos diretos e 1,722 mil empregos indiretos, US\$ 458 milhões em arrecadação de impostos e US\$ 7,7 bilhões em divisas de exportações (ABRAF, 2007).

A colheita florestal é um conjunto de operações que visa cortar e extrair árvores do local de derrubada até as margens das estradas ou cursos d'água (MACHADO, 2002). É uma atividade complexa, dada à ocorrência de vários fenômenos climáticos, biológicos e relacionados ao sistema homem-máquina, que podem afetar a produtividade das máquinas e, consequentemente, os custos e a produção.

Segundo Tanaka (1986), a colheita florestal é um conjunto de operações realizadas no maciço florestal, visando preparar e transportar a madeira até o seu local de utilização, empregando-se técnicas e padrões estabelecidos, tendo por finalidade transformá-la em produto final.

A produtividade de uma máquina de colheita de madeira irá depender de diversos fatores dos quais se destacam: extensão da área de trabalho; aspectos climáticos; capacidade de suporte do terreno; relevo; características das árvores; características da floresta e do sistema de colheita; e capacitação do operador (SEIXAS, 1998; MALINOVSKI et al., 2002).

A colheita florestal compreendida em suas três atividades básicas, ou seja, corte, extração e transporte, segundo Tanaka (1986), apresentase como o item de maior custo das atividades, podendo representar, aproximadamente, $80 \%$ do custo do metro cúbico de formação da floresta em condições de corte.

No Brasil, como afirmam Machado e Lopes (2000), a colheita e o transporte florestal são responsáveis por mais da metade do custo final da madeira colocada no centro consumidor. A seleção de máquinas e equipamentos e o desenvolvimento de sistemas operacionais constituem o grande desafio para a redução dos custos operacionais de colheita e transporte florestal.

Em diversos sistemas de toras curtas, o Harvester é a principal máquina utilizada na derrubada e processamento, que consiste, em alguns casos, no descascamento das árvores, no desgalhamento e no corte em toras de comprimento pré-determinado (traçamento), deixando as toras agrupadas e prontas para serem retiradas da área de colheita.

O custo operacional de uma máquina, segundo Harry et al. (1991), é o somatório de todos os custos resultantes de sua aquisição e operação. O seu conhecimento é uma etapa de fundamental importância para o planejamento e o controle de sua utilização. A variação deste custo é influenciada, principalmente, pela eficiência operacional e pela jornada de trabalho.

A redução dos custos da colheita florestal é, segundo Rezende et. al. (1997), essencial para qualquer empresa e uma análise detalhada desses custos tem um papel importante no seu entendimento.

O objetivo principal deste trabalho foi avaliar técnica e economicamente o Harvester na colheita florestal de madeira de eucalipto em diferentes condições de topografia e produtividade florestal.

\section{MATERIAL E MÉTODOS}

O presente trabalho foi realizado em áreas de operação de colheita florestal pertencentes à empresa CENIBRA, produtora de celulose, cujos povoamentos florestais, objetos deste estudo, encontram-se localizados no centro-nordeste mineiro, nas cidades de Divinolândia de Minas, Sabinópolis e Guanhães, no Estado de Minas Gerais, entre os paralelos $22^{\circ} 55^{\prime}$ de latitude sul, $48^{\circ} 50^{\prime}$ de longitude oeste

As áreas de coleta de dados são caracterizadas pela topografia montanhosa, altitudes variando de 600 a $800 \mathrm{~m}$, clima subtropical úmido, precipitação média anual de $1.200 \mathrm{~mm}$ sendo o período chuvoso de novembro a janeiro e o período seco de julho a setembro. Na região predomina o solo do tipo Latossolo VermelhoAmarelo. 
Foi utilizado um Harvester, da marca John Deere, modelo 1270 D, tração 6 x 6 equipado com pneus e motor de $160 \mathrm{~kW}$, em regime de 1400 a 2000 rpm, com um cabeçote de corte modelo 762 $\mathrm{C}$, conforme ilustrado na Figura 1.

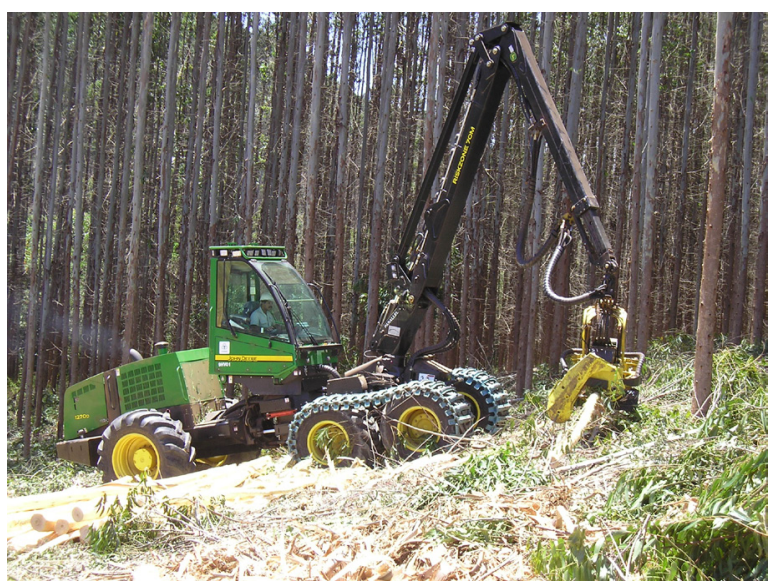

Figura 1. Harvester realizando colheita de eucalipto em terreno inclinado.

A máquina foi utilizada no sistema de toras curtas, executando as atividades de corte, descasque, desgalhamento e seccionamento das árvores. As toras foram cortadas com $4,40 \mathrm{~m}$ de comprimento, um diâmetro mínimo de 0,04 m e máximo de 0,45 $\mathrm{m}$, segundo o fabricante do cabeçote. A seqüência de trabalho foi: posicionar o cabeçote, segurar a árvore, realizar o corte, direcionar queda da árvore e todo processamento da árvore à esquerda da máquina. $\mathrm{O}$ eito de trabalho era composto de quatro fileiras de árvores. A madeira, após o processamento, foi depositada à esquerda do sentido de deslocamento da máquina.

O estudo de tempo e movimentos tem por finalidade dividir e quantificar o tempo gasto em cada atividade realizada pela colhedora. As observações foram feitas durante o trabalho em toda a parcela, em intervalos de 15 segundos. As atividades foram divididas em deslocamento, posicionamento do cabeçote, corte, tombamento, descasque, toragem, pausa técnica e pausa comum.

Para a quantificação do rendimento operacional foi cronometrado o tempo gasto pelo Harvester para processar cada parcela, sendo o tempo iniciado no momento em que o cabeçote era posicionado na primeira árvore e encerrado após processar a última tora da última árvore da parcela. No início de cada parcela havia uma pequena pausa no ritmo de trabalho, entre 30 e 60 segundos, para ativação do contador de volume e número de árvores do programa Timbermatic 300, instalado no computador da máquina para a mensuração do volume cortado.

Através deste programa, foi armazenado e coletado o volume (sem casca) e número de árvores colhido em cada parcela, obtendo-se o volume por árvore. Estes dados foram comparados aos valores encontrados no inventário apenas para checagem da eficiência do sistema, pois os dados medidos no inventário das parcelas é que foram usados nas análises.

Diante do volume cortado, do número de árvores e do tempo gasto em cada parcela, foi calculado o volume e o número de árvores cortadas por hora efetiva de trabalho em cada parcela e em cada situação.

$\mathrm{Na}$ determinação dos custos operacionais foi utilizado o método contábil, o qual utiliza valores estimados e reais. Os custos fixos (depreciação e juros) foram estimados pela metodologia proposta por Machado e Malinovski (1988).

Os juros ( $\left.\mathrm{J}=\mathrm{US} \$ \mathrm{he}^{-1}\right)$ foram calculados pela aplicação de uma taxa de juros ao investimento, correspondente ao capital proporcionado por agência financeira:

$J=\frac{(C a \times i \times f)}{V u}$

em que

$C a=$ custo de aquisição da máquina (US\$);

he $=$ horas efetivas de trabalho;

$i=$ taxa anual de juros $(\%)$;

$f=$ fator de correção; e

$V u=$ vida útil da máquina (horas).

Para efeito de cálculo, foram considerados:

$C a=\mathrm{US} \$ 485.714,29$;

$i=12 \%$ a.a.;

$f=0,6$ (correção para juros compostos); e $V u=18.000$ horas.

O método de depreciação usado foi o linear, em que o valor depreciável é obtido ao

\section{REVENG} 412-422 p. 
se subtrair do valor de aquisição da máquina seu valor residual $\left(\mathrm{D}=\mathrm{US} \$ \mathrm{he}^{-1}\right)$. Dividindo o valor depreciável pela vida útil estimada, obtém-se a quota de depreciação a ser deduzida anualmente:

$D=\frac{(C a-V r)}{V u}$

em que

$C a=$ custo de aquisição da máquina (US\$);

$V r=$ valor residual (US\$); e

$V u=$ vida útil (horas).

Para efeito de cálculo, foi considerado:

$V r=20 \%$ de $C a$

Os custos de mão-de-obra foram calculados pela seguinte fórmula:

$M D O=\left[\frac{S o p \times E s}{H T M}\right]$

em que

$M D O=$ custo de mão-de-obra por hora efetiva (US\$ he ${ }^{-1}$ );

Sop $=$ somatório dos salários mensais dos operadores (US\$);

$E s=$ taxa de encargos sociais (\%); e

$H T M=$ horas efetivas trabalhadas no mês (h).

Os custos de manutenção por hora trabalhada foram determinados pela fórmula a seguir:

Man $=\frac{(\text { Sof } \times E S)+O f f}{H T M}$

em que

Man = custo de manutenção por hora efetiva $\left(\mathrm{US} \$ \mathrm{he}^{-1}\right)$; Sof = somas dos salários mensais dos mecânicos (US\$);

$E s=$ taxa de encargos sociais (\%);

Off $=$ despesas diversas de oficina e serviços de terceiros (US\$); e
$H T M=$ horas efetivas trabalhadas no mês (h).

As despesas com peças foram assim determinadas:

$$
\text { Peças }=C o m b \times p
$$

em que

Peças $=$ valor com gastos em peças (US\$);

$C o m b=$ valor com gastos em combustível (US\$); e $f p=$ fator de relação histórico $(0,5)$.

Os gastos com combustível foram determinados pela seguinte fórmula:

$C o m b=C m m \times P u$

em que

$C o m b=$ custo com combustível por hora efetiva (US\$ he ${ }^{-1}$ );

$\mathrm{Cmm}=$ consumo médio horário da máquina por hora efetiva $\left(\mathrm{L} \mathrm{he}^{-1}\right)$; e

$P u=$ preço por litro de combustível (US\$ L ${ }^{-1}$ ).

A fórmula a seguir foi usada na obtenção do custo com gastos com lubrificantes, graxas e óleos hidráulicos:

$O H L=C o m b \times f$

em que

$O H L=$ custo de óleos hidráulicos, graxas e lubrificantes (US\$);

Comb $=$ custo com combustível por hora efetiva (US\$ he ${ }^{-1}$ ); e

$f=$ fator de relação histórico $(0,25)$.

Determinação dos custos de extração $\left(\mathrm{CC}=\mathrm{US} \$ \mathrm{~m}^{-3}\right)$.

$C E=\frac{(J+D+M D O+M a n+P e c ̧ a s+C o m b+O H L)}{\operatorname{Pr} o d}$

em que

$C C=$ custo de colheita $\left(\mathrm{US} \$ \mathrm{~m}^{-3}\right)$;

$J=$ custo com juros (US\$ he $\left.{ }^{-1}\right)$; 
$D=$ custo de depreciação (US\$ he ${ }^{-1}$ );

$M D O=$ custo com mão-de-obra $($ US $\$$ he-1);

Peças $=$ custos com peças $\left(\right.$ US $\$$ he $\left.{ }^{-1}\right)$;

$C o m b=$ custos com combustível (US\$ he ${ }^{-1}$ );

$O H L=$ custos com lubrificantes, graxas e óleo hidráulico (US\$ he ${ }^{-1}$ ); e

Prod $=$ produtividade $\left(\mathrm{m}^{3} \mathrm{he}^{-1}\right)$;

Foi utilizada a amostragem casual simples em nove diferentes situações, relacionando produção da floresta com declividade. As classes de declividade foram divididas em plano até 10 graus, onduladas entre 10,1 e 20 graus e acidentado acima de 20,1 graus. As classes de produção por hectare foram divididas em baixa abaixo de $210 \mathrm{~m}^{3} \mathrm{ha}^{-1}$, média entre $211 \mathrm{e} 320 \mathrm{~m}^{3} \mathrm{ha}^{-1} \mathrm{e}$ alta acima de $321 \mathrm{~m}^{3} \mathrm{ha}^{-1}$.

\section{RESULTADOS E DISCUSSÃO}

Foram avaliadas 121 parcelas, totalizando 12.200 covas, com uma sobrevivência média de $89 \%$. Foram medidas, aproximadamente, 10.858 árvores. $\mathrm{O}$ Quadro 1 apresenta o número de parcelas consideradas para cada uma das nove situações avaliadas.

Com base no estudo de tempo e movimento foi possível determinar o percentual parcial gasto em cada atividade, assim foi possível determinar o tempo gasto em cada etapa do processo, podendo assim, aperfeiçoá-las e consequentemente aumentar a produção do conjunto operador - máquina.

Os resultados do estudo de tempo e movimento foram demonstrados em porcentagem, devido ao tempo total de coleta diferir em cada parcela. $\mathrm{O}$ tempo médio para processamento das parcelas foi de 49,14 minutos, o tempo mínimo apresentando foi de 36,87 e o máximo foi de 65,73 , com um coeficiente de variação de 14,2. O erro entre o número de observações esperadas e as observadas foi de 1,1\%. $\mathrm{Na}$ Figura 2 apresenta-se a média geral do percentual de tempo em cada etapa do processamento das árvores.

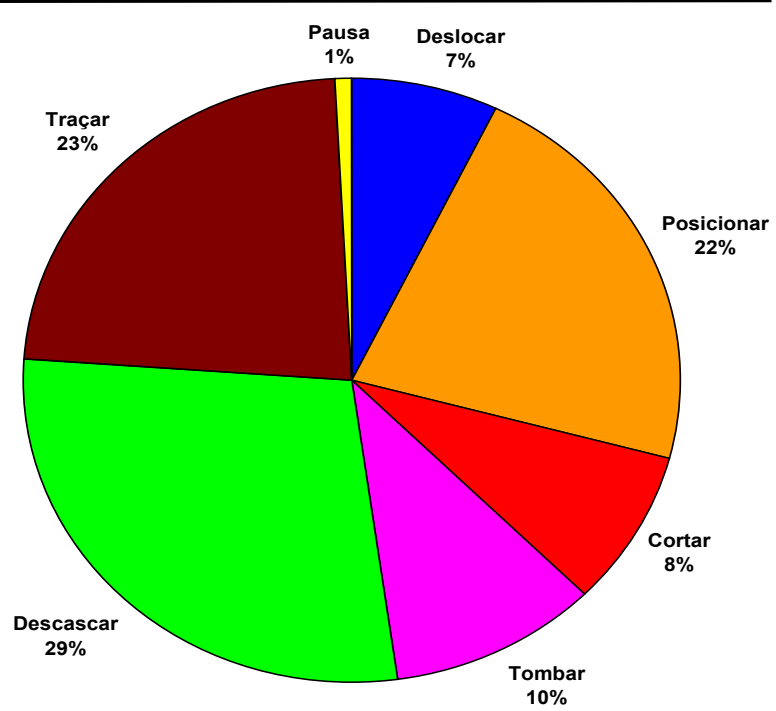

Figura 2. Etapas do processamento de árvores de eucalipto pela máquina Harvester.

Para visualizar a provável influência da declividade do terreno e da produção florestal nos percentuais de tempo de cada etapa da atividade, agruparam-se os dados em classes de relevo e produção.

$\mathrm{Na}$ Figura 3, demonstra-se a influência da declividade no tempo gasto nas etapas do processamento das árvores. Observa-se, quando agrupado as classes de declividade, que o tempo gasto para deslocamento aumenta cerca de $100 \%$, indicando a resistência oferecida pela inclinação do terreno ao deslocamento da máquina. Nas demais etapas não existem grandes variações.

$\mathrm{Na}$ Figura 4, demonstra-se o agrupamento dos dados por classe de produção. O tempo de posicionamento do cabeçote diminui conforme aumenta o volume por hectare, pois o operador tem mais facilidade de posicionar o cabeçote em árvores mais grossas. $\mathrm{O}$ tempo despendido com o descasque aumenta com o aumento do volume da floresta, devido à presença de galhos de maior diâmetro $\mathrm{e}$ pela maior dificuldade na movimentação dos rolos, devido ao aumento do peso das árvores.

Quadro 1. Total de parcelas em função da classe de produtividade e relevo

\begin{tabular}{cccc}
\hline Classe de produtividade & Relevo Plano & Relevo Ondulado & Relevo Acidentado \\
\hline Baixa & 10 & 13 & 11 \\
\hline Média & 16 & 18 & 11 \\
\hline Alta & 21 & 11 & 10 \\
\hline
\end{tabular}




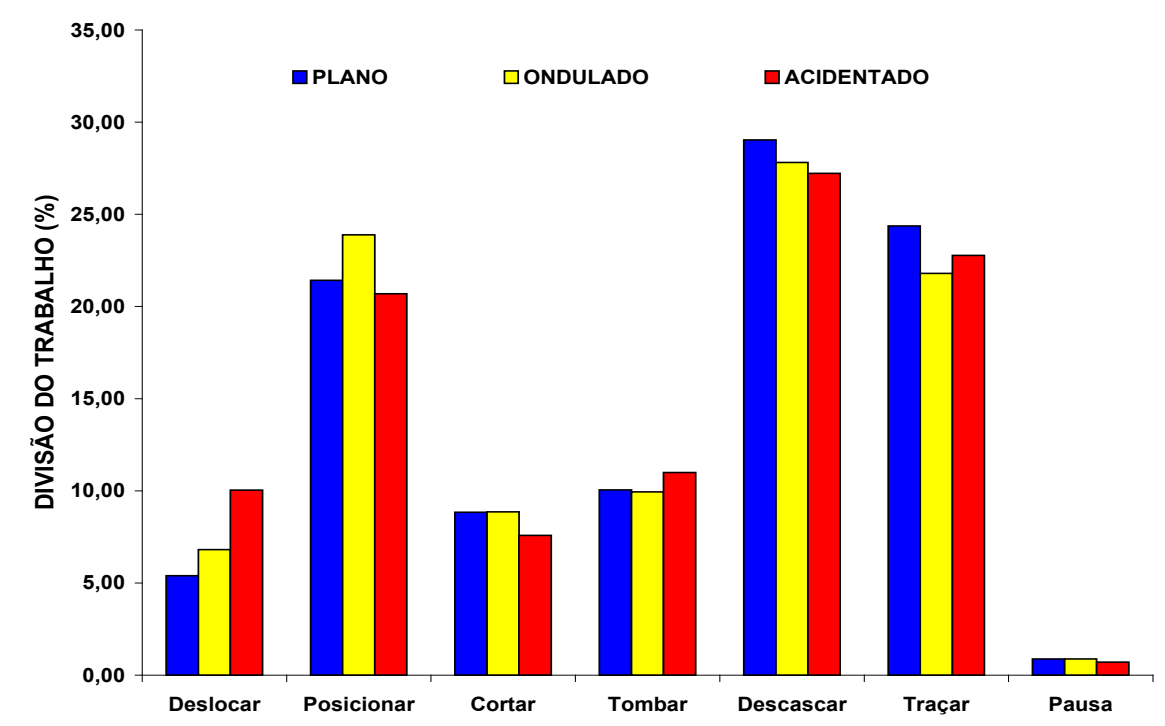

Figura 3. Etapas de trabalho do Harvester na colheita do eucalipto por classes de declividade do terreno.

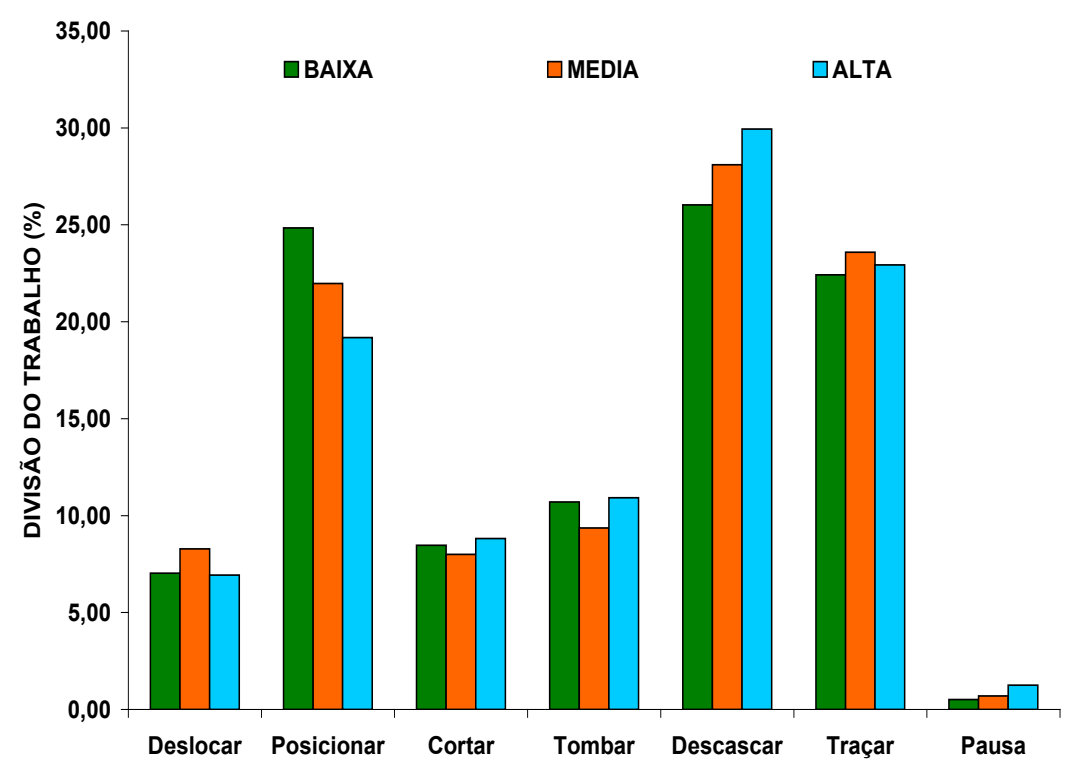

Figura 4. Etapas de trabalho do Harvester na colheita do eucalipto por classes de produção da floresta.

Através do estudo de tempo determinou-se que as atividades de descasque, traçamento e posicionamento do cabeçote representaram $28,3 \%, 23,1 \%$ e $22,0 \%$, respectivamente, totalizando $73,4 \%$. Estes dados são de suma importância para aumentar a produtividade dos equipamentos.

O ganho de produtividade no descascamento está diretamente relacionado à velocidade dos rolos de tração do cabeçote de corte, além das características naturais da árvore, tais como a qualidade da desrama natural e homogeneidade dos fustes.

Já o ganho de produtividade no traçamento está relacionado com a velocidade de giro da corrente e com a qualidade da afiação.

Com relação ao posicionamento do cabeçote, pode-se dizer que o volume individual das árvores é o principal fator de influência. A experiência e a habilidade do operador também podem influenciar no dispêndio de tempo entre uma árvore e outra.

Havia uma dúvida se a máquina ao chegar ao 
final do eito na parte superior de uma encosta, deveria descer a encosta derrubando árvores ou se deslocar até a base e reiniciar a derrubada de árvores subindo a encosta. A partir deste estudo, onde se contatou que o tempo gasto com o deslocamento da colhedora, cerca de $7 \%$ do tempo total, não causa grande impacto no ciclo da atividade, preocupações com um eventual retorno para iniciar um novo eito, são desnecessárias. Não se considerou aspectos de segurança da operação que devem ser analisados para cada situação

O tempo médio entre todas as nove situações para processar uma parcela de 100 árvores foi de 49,14 minutos. As parcelas analisadas apresentaram um volume médio de $23,01 \mathrm{~m}^{3}$, com base no volume fornecido pelo Timbermatic 300. O rendimento médio foi de 108,85 árvores e $28,00 \mathrm{~m}^{3}$ de madeira sem casca por hora efetiva de trabalho.

$\mathrm{Na}$ Figura 5 observa-se que o rendimento aumenta com o volume por hectare nas áreas com até 10 graus de declividade, porém a partir de uma inclinação de 10 graus pode-se notar que, por sofrer algum tipo de influência, diminui com o aumento da declividade. Nas florestas de alta produtividade, mas situadas em terrenos mais acidentados, há uma queda mais significativa no rendimento devido a restrições de estabilidade da máquina e também de força da máquina para sustentar o processamento árvores de maior porte, portanto mais pesadas.

Na Figura 6, ilustra-se a diminuição do número de árvores processadas por hora à medida que aumenta a inclinação do terreno e a produtividade da floresta. Esta diminuição é mais marcante nas florestas de baixa produtividade.

Analisando-se as Figuras 5 e 6 observa-se que nos terrenos planos com florestas de baixa produtividade, o número de árvores processadas por hora foi mais alto (Figura 6), mas isto não resulta em maior produção de madeira (Figura 5), devido ao baixo volume individual das árvores, mas também aponta que a máquina teria capacidade para processar um maior número de árvores por hora nas demais condições de terreno e produtividade florestal. Porém, isto não ocorreu. Nas áreas de terrenos ondulados e acidentados com florestas de média ou alta produtividade, o número de árvores processadas por hora foi menor que o alcançado nas áreas planas, tendo o maior volume individual das árvores compensando a perda, levando a uma relação entre o número de árvores processadas e a produção de madeira quase direta. Isto pode indicar que a máquina estaria trabalhando no seu limite técnico, sofrendo a influência do peso da árvore, diminuindo assim o rendimento.

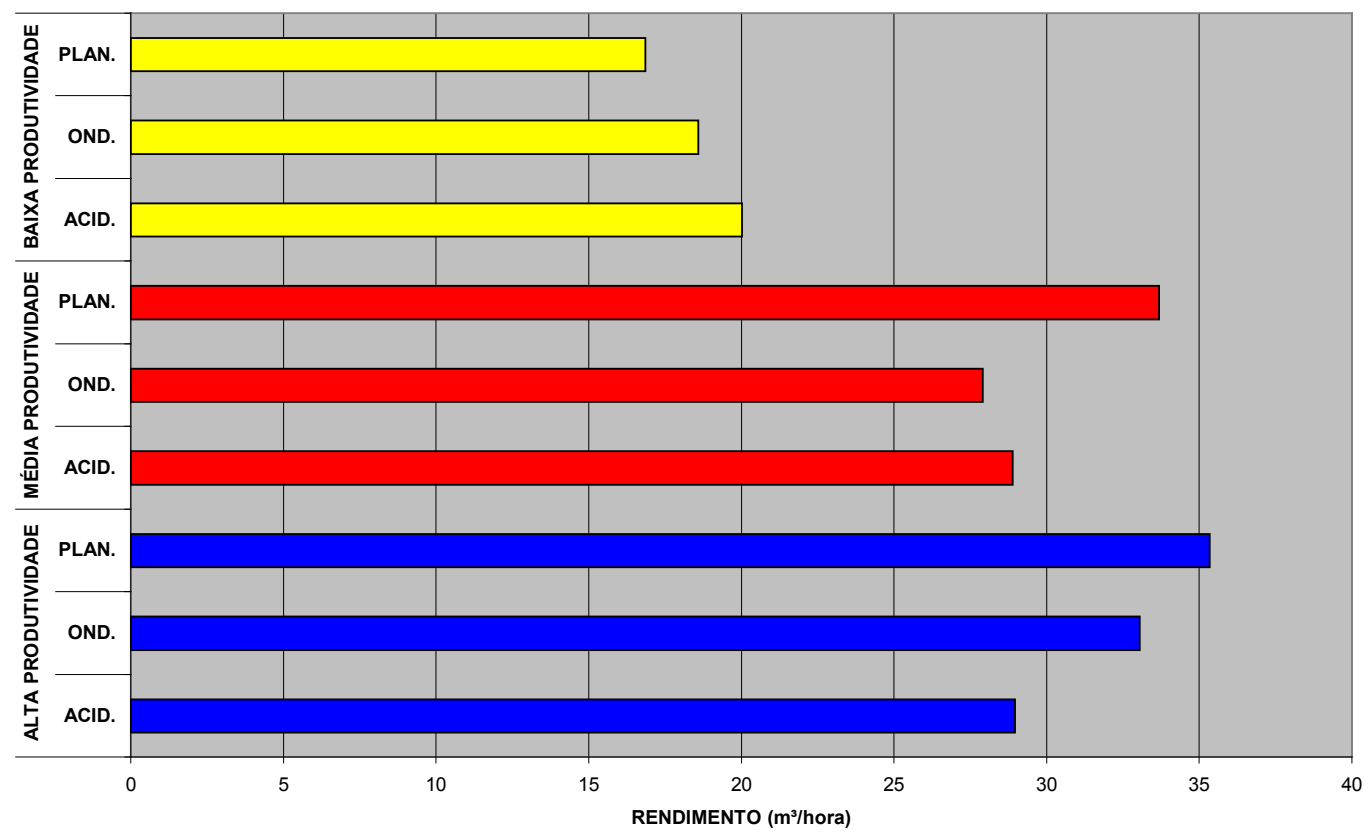

Figura 5. Rendimento $\left(\mathrm{m}^{3} \mathrm{~h}^{-1}\right)$ do Harvester na colheita de eucalipto em diferentes classes de produtividade florestal e declividade do terreno.

418 REVENG

$412-422 \mathrm{p}$

ENGENHARIA NA AGRICULTURA, VIÇOSA - MG, V.20 N.5, SETEMBRO / OUTUBRO 2012 


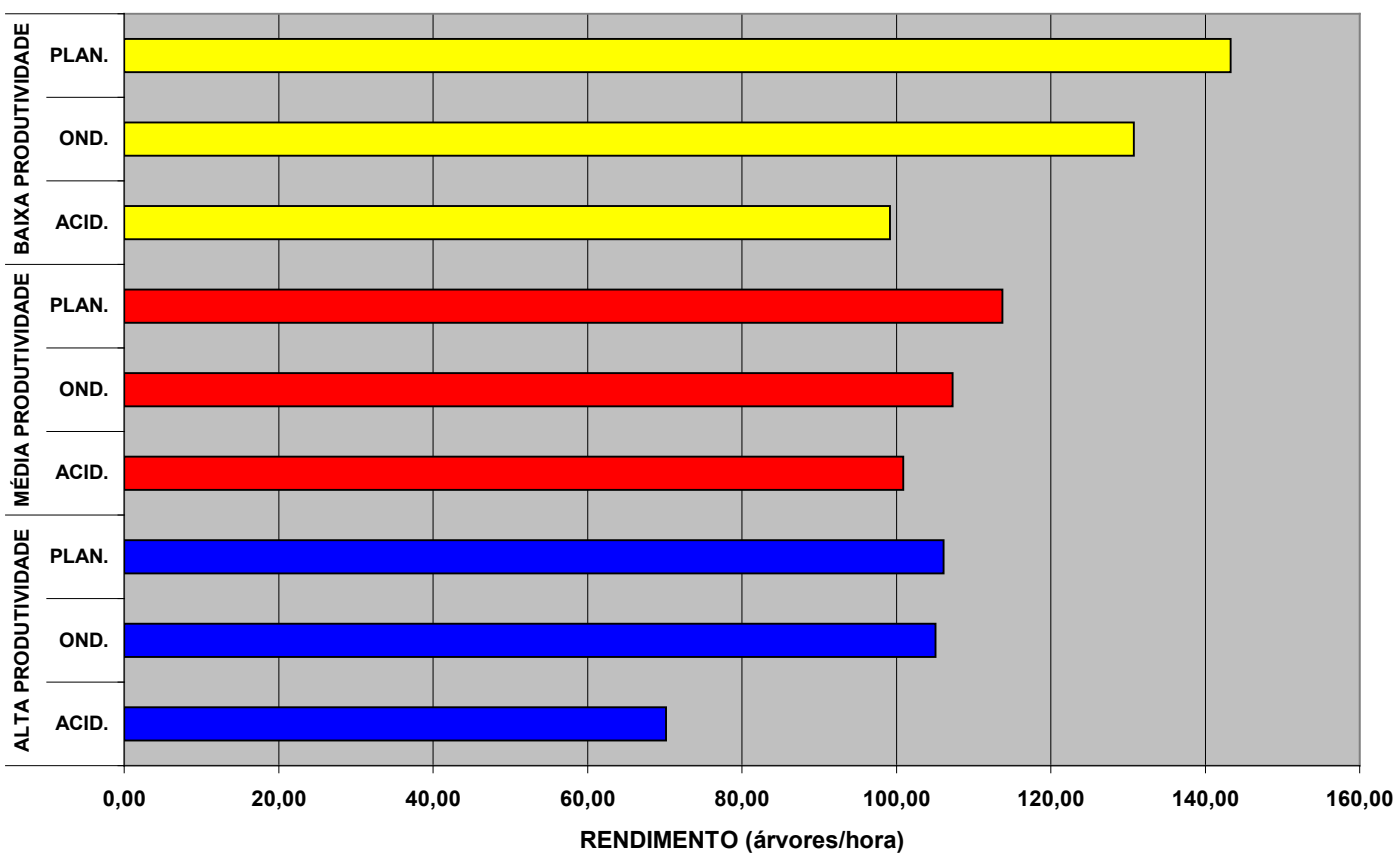

Figura 6. Rendimento (árvores $\mathrm{h}^{-1}$ ) do Harvester na colheita de eucalipto em diferentes classes de produtividade florestal e declividade do terreno.

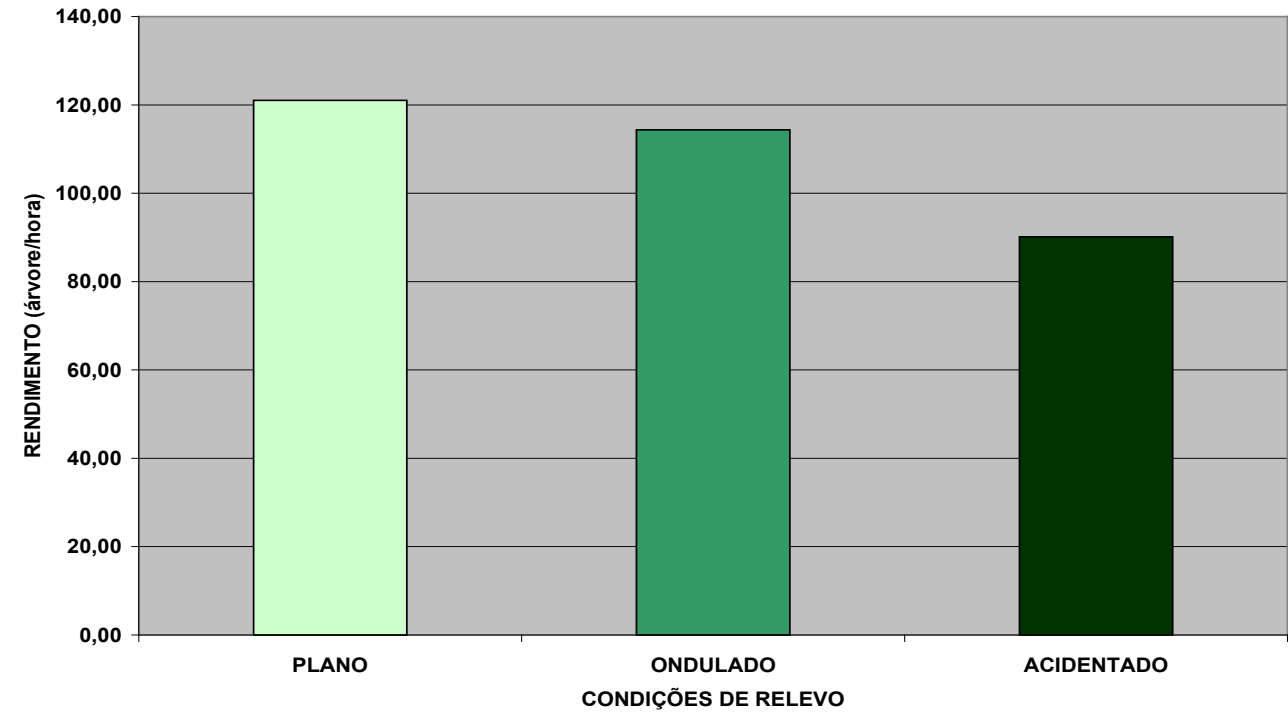

Figura 7. Rendimento (árvores $\mathrm{h}^{-1}$ ) do Harvester na colheita de eucalipto em função das condições de relevo.

Agrupando-se os dados em cada situação de inclinação do terreno ou produtividade das florestas, podem-se visualizar mais facilmente os efeitos individuais de cada situação sobre o rendimento em árvores por hora e metros cúbicos por hora.

Nas Figuras 7 e 8 , observa-se que o rendimento em número de árvores processadas e em metros cúbicos por hora diminui com o aumento da declividade, que torna a máquina mais instável no terreno. Esta análise isolada permite a conclusão óbvia que o rendimento é maior quanto mais plano for o terreno. 


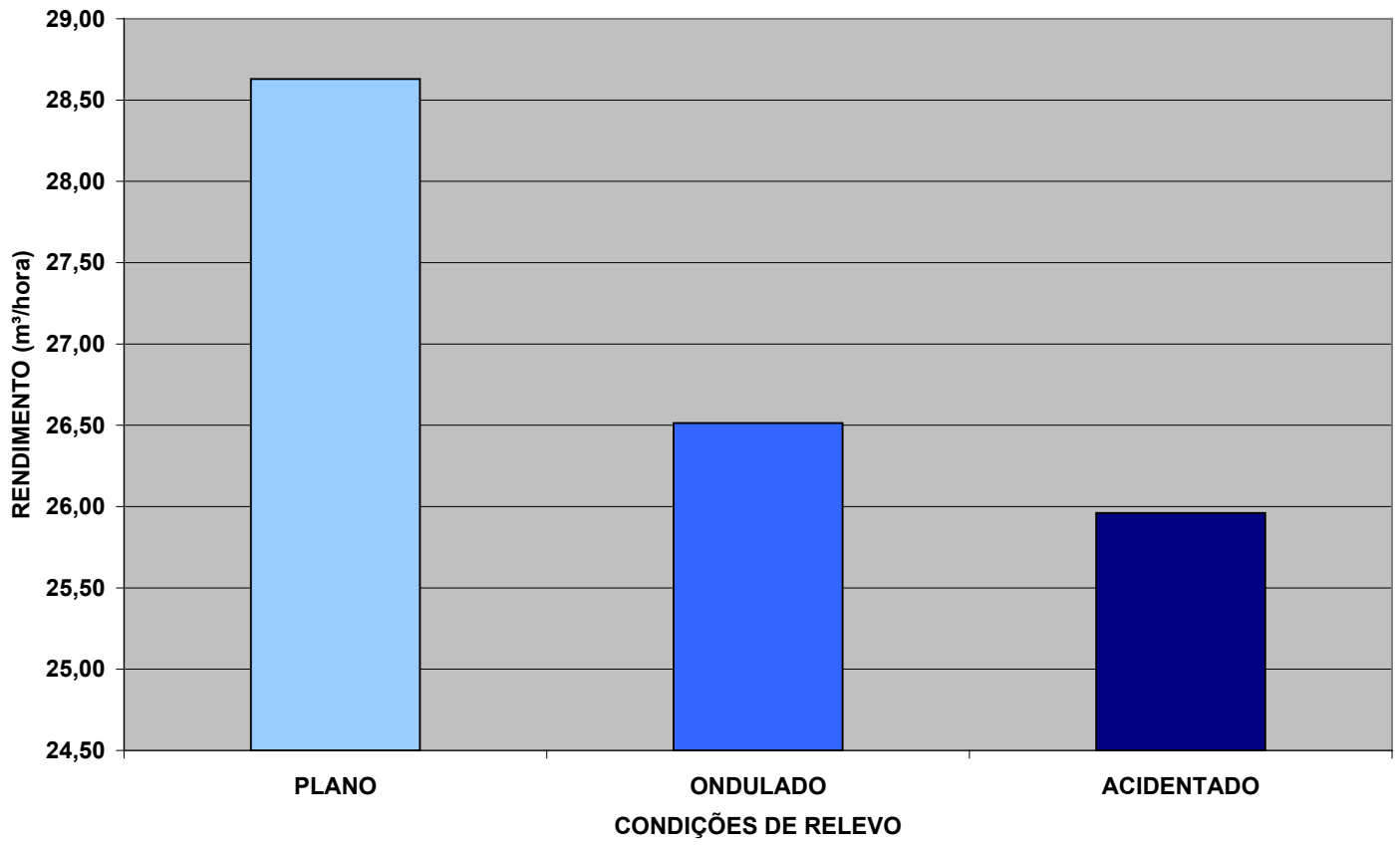

Figura 8. Rendimento $\left(\mathrm{m}^{3} \mathrm{~h}^{-1}\right)$ do Harvester na colheita de eucalipto em função das condições de relevo.

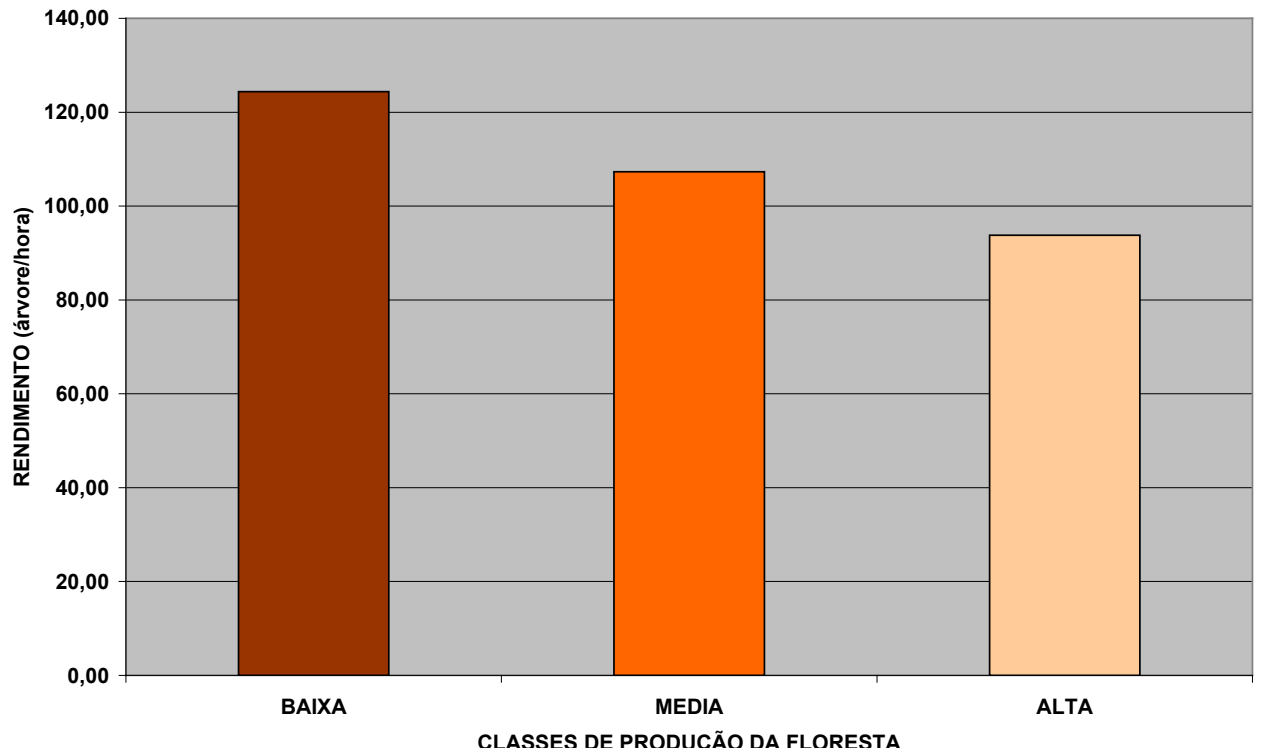

Figura 9. Rendimento (árvores $\mathrm{h}^{-1}$ ) do Harvester na colheita de eucalipto em função da produtividade florestal.

Na Figura 9, observa-se que o rendimento, em número de árvores processadas por hora, diminui com o aumento da produção da floresta, pois o aumento do volume individual aumenta o peso das árvores, por conseguinte dificulta mais o processamento. Na Figura 10 o rendimento em volume $\left(\mathrm{m}^{3} \mathrm{~h}^{-1}\right)$ aumenta com a produtividade da floresta, pois as árvores apresentam um volume individual maior, compensando a queda no rendimento em número de árvores processadas por hora. No Quadro 3 estão compilados os custos operacionais do Harvester.

\section{REVENG}

412-422 p. ENGENHARIA NA AGRICULTURA, VIÇOSA - MG, V.20 N.5, SETEMBRO / OUTUBRO 2012 


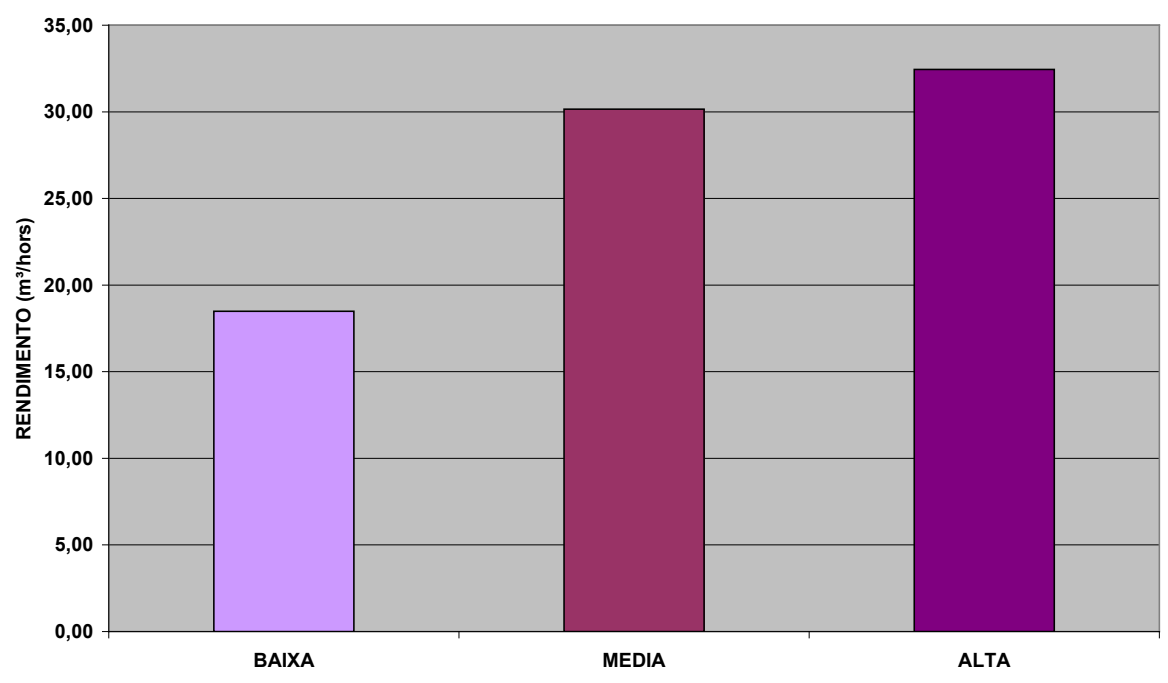

Figura 10. Rendimento $\left(\mathrm{m}^{3} \mathrm{~h}^{-1}\right)$ do Harvester no processamento de eucalipto em função da produtividade florestal.

Quadro 3. Custo operacional do Harvester

\begin{tabular}{|llrrr|r|}
\hline CUSTOS FIXOS & FÓRMULAS & & $\mathbf{R} \$$ & $\mathbf{4 1 , 1 8}$ & $\mathbf{\$ 2 3 , 5 3}$ \\
\hline Juros & $\mathrm{J}=(\mathrm{Va} \cdot \mathrm{i} . \mathrm{f}) / \mathrm{Vu}$ & $\mathrm{J}$ & $\mathrm{R} \$$ & 3,40 & $\$ 1,94$ \\
\hline Depreciação & $\mathrm{D}=(\mathrm{Va}-\mathrm{Vr}) / \mathrm{Vu}$ & $\mathrm{D}$ & $\mathrm{R} \$$ & 37,78 & $\$ 21,59$ \\
\hline Valor de Aquisição & & $\mathrm{Va}$ & $\mathrm{R} \$$ & $850.000,00$ & $\$ 485.714,29$ \\
\hline Taxa de juros (\% a.a.) & & $\mathrm{i}$ & 0,12 & 0,12 \\
\hline Fator de correção & & $\mathrm{f}$ & 0,60 & 0,60 \\
\hline Via Útil (em horas) & & $\mathrm{Vu}$ & $18.000,00$ & $18.000,00$ \\
\hline Valor Residual & $20 \%$ & $\mathrm{Vr}$ & $\mathrm{R} \$ 170.000,00$ & $\$ 97.142,86$ \\
\hline
\end{tabular}

\begin{tabular}{|c|c|c|c|c|c|}
\hline CUSTOS VARIÁVEIS & & & $\mathbf{R} \$$ & 186,83 & $\$ 106,76$ \\
\hline Operadores & $\mathrm{MDO}=($ Sop. Es $) / \mathrm{HTM}$ & MDO & $\mathrm{R} \$$ & 28,29 & $\$ 16,16$ \\
\hline Soma salários mensais operadores & & Sop & $\mathrm{R} \$$ & $4.500,00$ & $\$ 2.571,43$ \\
\hline Encargos Sociais (120\%) & $120 \%$ & Es & $\mathrm{R} \$$ & $5.400,00$ & $\$ 3.085,71$ \\
\hline Horas efetivas trabalhadas mensais & & HTM & & 420,00 & 420,00 \\
\hline Manutenção & Man $=(($ Sof . Es $)+$ Off $) /$ HTM & Man & $\mathrm{R} \$$ & 61,35 & $\$ 35,06$ \\
\hline Soma salários mensais mecânicos & & Sof & $\mathrm{R} \$$ & $4.500,00$ & $\$ 2.571,43$ \\
\hline Encargos Sociais (120\%) & & Es & $\mathrm{R} \$$ & $5.400,00$ & $\$ 3.085,71$ \\
\hline Despesas de oficina & Off $=\mathrm{D} \times \mathrm{HTM}$ & Off & $\mathrm{R} \$$ & $15.866,67$ & $\$ 9.066,67$ \\
\hline Peças & Peças $=$ Comb.$F p$ & Peças & $\mathrm{R} \$$ & 48,60 & $\$ 27,77$ \\
\hline Fator de relação histórico & & $\mathrm{Fp}$ & & 1,50 & \\
\hline Gastos com combustível & Comb $=\mathrm{Cmm} \times \mathrm{Pu}$ & Comb & $\mathrm{R} \$$ & 32,40 & $\$ 18,51$ \\
\hline Consumo médio horário & & $\mathrm{Cmm}$ & & 18,00 & \\
\hline Preço por litro & & $\mathrm{Pu}$ & $\mathrm{R} \$$ & 1,80 & 1,03 \\
\hline Gastos com óleos hidráulicos & $\mathrm{OHL}=\mathrm{Comb} \times \mathrm{f}$ & $\mathrm{OHL}$ & $\mathrm{R} \$$ & 16,20 & $\$ 9,26$ \\
\hline fator de relação histórico & & $\mathrm{Fp}$ & & 0,50 & \\
\hline CUSTO HORÁRIO & $\mathrm{CH}=(\mathrm{J}+\mathrm{D}+\mathrm{MDO}+$ Man + Peças + Comb + OHL $)$ & & $\mathbf{R} \mathbf{S}$ & 228,01 & $\$ 130,29$ \\
\hline
\end{tabular}

\section{CONCLUSÕES}

- O volume individual das árvores e a declividade do terreno são os fatores que mais influenciam no rendimento operacional da máquina Harvester na colheita de florestas de eucalipto;

- O deslocamento entre árvores não afetou o rendimento da máquina, mostrando que arranjos espaciais no plantio não interferem no rendimento, podendo-se inferir que uma densidade entre 800 e 1.200 plantas por hectare é aceitável; e 
- A queda no rendimento do Harvester com o aumento da produtividade florestal, não pode ser explicada com o tempo de deslocamento da máquina e nem pela declividade do terreno.

\section{REFERÊNCIAS BIBLIOGRÁFICAS}

ABRAF. Anuário Estatístico da ABRAF: ano base 2006/ABRAF. - Brasília, 2007. 80p.

AMABILINI, V.D. Utilização do Harvester na exploração florestal. In: SIMPÓSIO BRASILEIRO SOBRE EXPLORAÇÃO E TRANSPORTE FLORESTAL. Anais... Belo Horizonte. 1991. p 349-364.

HARRY, G.G.; FONTES, J.M.; MACHADO, C.C.; SANTOS S.L. Análise dos efeitos da eficiência no custo operacional de máquinas florestais. In: SIMPÓSIO BRASILEIRO SOBRE EXPLORAÇÃO E TRANSPORTE FLORESTAL. 1. Anais... Belo Horizonte: UFV/SIF, 1991.

LEITE, A.M.P.; LIMA, J.S.S. Mecanização. In: Colheita Florestal, Viçosa, Editora UFV, 2002,600p.

MACHADO, C.C.; LOPES, E.S. Análise da influência do comprimento de toras de eucalipto na produtividade e custo da colheita e transporte florestal. Revista Cerne, Lavras, v.6, n.2, p.124-
129, 2000.

MACHADO, C.C.; MALINOVSKI, J.R. Ciência do trabalho florestal. Viçosa, MG: Universidade Federal de Viçosa, 1988. 65 p.

MACHADO, C.C. O setor florestal brasileiro. In: MACHADO, C.C. (Ed.). Colheita florestal. Viçosa, MG: UFV, 2002. 468p.

MALINOVSKI, J.R.; CAMARGO, C.M.S.; MALINOVSKI, R.A. Sistemas. In: Machado, C.C. (Ed.) Colheita florestal. Viçosa: UFV, 2002. Cap. 6, p.145-67.

REZENDE, J.L.; FIEDLER, N.C.; MELLO, J.M.; SOUZA, A.P. Análise técnica e de custos de métodos de colheita e transporte florestal. Lavras: UFLA, 1997. 50p. (Boletim Agropecuário, 22)

SEIXAS, F. Mecanização e exploração florestal. Apostila de Colheita Florestal. LCF/ESALQ/USP. 1998. 130p.

SILVEIRA, G.M. da. Os cuidados com o trator. Viçosa: Aprenda Fácil, 2001. (Série Mecanização, 1). $312 \mathrm{p}$.

TANAKA, O.P. Exploração e transporte da cultura do eucalipto. Informe Agropecuário, n.141, p.24-30, 1986. 